\title{
SOMATOSTATIN-LIKE IMMUNOREACTIVITY CHARACTERIZES NEURONS OF THE NUCLEUS RETICULARIS THALAMI IN THE CAT AND MONKEY ${ }^{1}$
}

\author{
ANN M. GRAYBIEL ${ }^{*, 2}$ AND ROBERT P. ELDE $\ddagger$ \\ * Department of Psychology and Brain Science, Massachusetts Institute of Technology, Cambridge, Massachusetts 02139 and \\ $\$$ Department of Anatomy, University of Minnesota, Minneapolis, Minnesota 55455
}

Received December 13, 1982; Accepted January 28, 1983

\begin{abstract}
This report presents immunohistochemical evidence for the occurrence of a somatostatin-related peptide in neurons of the thalamic reticular nucleus, a nucleus known to modulate thalamic activity by $\gamma$-aminobutyric acid (GABA)-mediated inhibition. In eight cats and kittens and one rhesus monkey, sections through the nucleus reticularis thalami and adjoining regions of the thalamus, subthalamus, and mesencephalic tegmentum were incubated in anti-somatostatin antisera and processed by the Sternberger peroxidase-antiperoxidase or Coons direct immunofluorescence methods. In each brain, intense somatostatin-like immunoreactivity was found in neurons of the nucleus reticularis thalami. The immunoreactivity was localized to the perinuclear region of the neurons in both species. Somatostatin-like immunoreactivity appeared in only a sharply restricted subset of other zones thought to have an embryologic origin in the ventral thalamus (including, in the cat, two nuclei that project to the amygdala: the nucleus subparafascicularis and the peripeduncular nucleus of the mesodiencephalic tegmentum). An incidental finding was that the pars lateralis of the cat's substantia nigra contains a system of fine fibers expressing somatostatin-like immunoreactivity.

In the nucleus reticularis of the cat, immunoreactive neurons were observed regularly in experiments with antisera generated against somatostatin-14 and were also found in preliminary experiments with an antiserum against the "non-somatostatin" (1 to 14) sequence of somatostatin-28. These observations, together with the perinuclear location of the immunoreactivity, suggest that a somatostatin precursor molecule may be present or at least that the neurons contain both the larger and smaller somatostatin-related peptides. The neurons of the nucleus reticularis also showed moderate acetylcholinesterase activity but were negative in tests of immunoreactivity to antisera raised against avian pancreatic polypeptide and Met-enkephalin. We conclude that the presence of somatostatin-like immunoreactivity may be a defining characteristic of the nucleus reticularis thalami and suggest that the functional activity of the neurons of the nucleus reticularis may involve not only a GABA mechanism but also the action of somatostatin or a related neuropeptide.
\end{abstract}

The nucleus reticularis of the thalamus lies like a shell around the lateral and anterior sides of the main thalamic mass so that its neurons stand in the path of the thalamic radiations. This remarkable physical arrangement has a

\footnotetext{
${ }^{1}$ This work was supported by grants from the National Science Foundation (BNS81-12125), National Institutes of Health (5-RO1EY02866 and DA02148), and the National Aeronautics and Space Administration (NAG2-124). We thank Dr. J. Kimmel for his generous contribution of antiserum against avian pancreatic polypeptide, Ms. Elaine Yoneoka, Ms. Dianne Sahagian, and Mr. Henry Hall for their skilled technical support, Ms. Ruma Ahmad-Mizra for her help with some of the tissue, and Mr. Hall for the photography.

${ }^{2}$ To whom correspondence should be addressed.
}

direct counterpart in the connections that neurons of the nucleus reticularis make: they are innervated by collaterals of the thalamocortical and corticothalamic fibers sweeping through the nucleus, and they project back upon the thalamus in an orderly and apparently topographic way (Ramon y Cajal, 1911, 1966; Scheibel and Scheibel, 1966; Jones, 1975; Montero et al., 1977). The nucleus reticularis thus lies in a key position both to monitor thalamocortical activity and to modulate this activity at its thalamic source. Physiological evidence strongly suggests that this modulation is inhibitory (Scheibel and Scheibel, 1966; Filion et al., 1969; Schlag and Wasak, 1971; Frigyesi and Schwartz, 1972; Purpura, 1972). In 1980, Houser and her colleagues proposed that 
the inhibition exerted by the nucleus reticularis operates by means of $\gamma$-aminobutyric acid (GABA) because they could demonstrate, in neurons of the nucleus, high immunoreactivity to the synthetic enzyme of the GABA mechanism, glutamic acid decarboxylase (GAD). We report here that at least the majority of neurons in the nucleus reticularis of the cat are also characterized by immunoreactivity to antisera prepared against somatostatin, a neuropeptide itself reported to have mainly inhibitory effects on neural and hormonal function (see Iversen et al., 1978a, b; Reichlin, 1980).

\section{Materials and Methods}

Somatostatin-like immunoreactivity was studied in the brains of five cats, three kittens ( 1 to 28 days old) and one adult rhesus macaque monkey fixed by perfusion with $4 \%$ paraformaldehyde in $0.1 \mathrm{~m}$ phosphate buffer $(\mathrm{pH}$ 7.4) to which $0.9 \%$ saline and $5 \%$ sucrose had been added. Two of the cats had received injections of colchicine (intraventricular or intrastriatal, 500 to $800 \mu \mathrm{g}$ in saline) 1 to 2 days previously. Trimmed blocks containing the thalamus and midbrain were briefly postfixed, washed overnight in $0.1 \mathrm{M} \mathrm{PO}_{4}$ buffer containing 5 to $20 \%$ sucrose, and cut on a freezing microtome in the transverse plane at 15 to $30 \mu \mathrm{m}$.

Most sections were incubated in either one of two antisera to somatostatin-14 (R176C, R176D) obtained from rabbits inoculated with the synthetic 14 -amino acid peptide coupled to keyhole limpet hemocyanin with carbodiimide (see Elde and Parsons, 1975; Arimura et al., 1978). A preliminary screening was also made on some sections (cat only) with an antiserum (A3b) to the "nonsomatostatin" (1 to 14) part of somatostatin-28 that was obtained from rabbits inoculated with $N$-Tyr-somatostatin-28 (1 to 14) coupled to keyhole limpet hemocyanin by carbodiimide condensation. Specificity of the R176 and $\mathrm{A} 3 \mathrm{~b}$ antisera for the two somatostatin-related peptides was tested by applying a 1:1000 dilution of antiserum to filter paper prepared by spotting various solutions of peptides followed by immobilization with formaldehyde vapor (Larsson, 1981). The peroxidase-antiperoxidase (PAP) method of Sternberger (1979) was used to detect binding of the antisera to the filter paper spots. Anti-somatostatin-14 bound only to somatostatin-14, whereas anti-somatostatin-28 (1 to 14) recognized only that peptide. Cross-reactivity between these two antisera and their respective antigens, if present, was less than $0.01 \%$.

For the immunohistochemistry, dilutions of the primary antisera in $0.1 \% \mathrm{PO}_{4}$ buffer containing $0.3 \%$ Triton $\mathrm{X}-100$ were chosen according to the results of trials (1:1000 to $1: 1200)$, and incubations were carried out for one to several days. Most of the sections were processed by the PAP method (Sternberger, 1979) according to protocols described in more detail elsewhere (Graybiel et al., 1981). After incubation in the primary antiserum, the sections were exposed to goat anti-rabbit IgG (Miles Laboratories, Elkhart, IN), then to rabbit PAP (Miles; Sternberger-Meyer, Garretsville, MD), and finally to diaminobenzidene (Graham and Karnovsky, 1966). A few sections were incubated with fluorescein isothiocyanate (FITC) according to the indirect immunofluorescence technique (Coons, 1958), and a few other sections were carried through the PAP protocol of Pickel et al. (1975, 1976) with either $0.2 \%$ or $2 \%$ Triton X-100 preincubation. Series of adjoining sections were prepared by Nissl or thiocholine methods (see Graybiel and Berson, 1980). A few sections were also prepared by the PAP method following incubation in antisera generated against Metcnkephalin (see Graybiel et al., 1981) or avian pancreatic polypeptide (APP; kind gift of Dr. J. Kemmel). Finally, sections from a cat pretreated with diisopropyl fluorophosphate (DFP) $6 \mathrm{hr}$ before perfusion were available (A. M. Graybiel and M. -F. Chesselet, manuscript in preparation) and were studied for the presence of acetylcholinesterase in neurons of the nucleus reticularis.

Controls for the PAP series were carried out by $(a)$ omitting the primary antiserum from the initial incubation step, $(b)$ diluting the primary antiserum in steps $(1: 1,000,1: 5,000,1: 10,000)$, and (c) carrying out the primary incubation in the presence of synthetic somatostatin (Sigma Chemical Co., St. Louis, MO). These procedures were carried out for the somatostatin-14 antiserum only and did not permit us to distinguish among different molecular species known to have somatostatin-like immunoreactivity (Speiss and Vale, 1980); nor did they fully insure against the possibility that the antisera used crossreacted with molecules antigenically related to, but different from, the family of somatostatin-immunoreactive molecules. For this reason, we restrict the definition of somatostatin-like immunoreactivity in the present study to immunoreactivity to antisera R176C and R176D generated against somatostatin-14 and, for the preliminary experiments mentioned, immunoreactivity to antiserum A3b generated against somatostatin-28 (1 to 14).

\section{Results}

Somatostatin-like immunoreactivity appeared in neurons of the nucleus reticularis in all brains reacted with the antisera directed against somatostatin-14, and was intense enough to be visible at low magnification in both FITC and PAP preparations. Figure 1 illustrates the typical appearance of FITC-labeled neurons in the nucleus reticularis of a 28-day-old kitten, and Figure 2 shows PAP preparations from one of the adult cats (Fig. $2 A$ ) and from the rhesus macaque (Fig. $2 B$ ). In both cat and monkey, the immunoreactive neurons lay singly or in small clusters alongside unreactive fiber bundles, and comparisons with adjoining sections stained for Nissl substance gave the impression that virtually all of the neurons in the nucleus reticularis were stained. In two cats we tried to test this directly by making photographs of fluorescence patterns in FITC sections, then staining the sections with thionin and photographing the same fields a second time. As indicated in Figure 3, there were matches in the fluorescence material for nearly all of the Nissl-stained neurons cut through the plane of nucleolus.

It was striking that most of the immunoreactivity in the nucleus reticularis was confined to the cell bodies rather than to the neuropil in which they lay embedded. Within the neurons, the reaction product was concentrated mainly in cytoplasmic skeins and vesicles around the nucleus, and in some primary dendrites. This was very obvious in the PAP sections (see Fig. $4, A, C$, and 
$D$ ), where the neuropil was only slightly darker than the penetrating bundles of radiation fibers. Only rarely (see Fig. $4 C$ ) were immunoreactive fibers visible in the nucleus reticularis itself or in the adjoining nuclei of the dorsal thalamus proper.

This pattern of perikaryal labeling was a distinctive characteristic of immunoreactivity in the nucleus reticularis. Elsewhere in the same sections (for example, as shown in Fig. 4, $B$ and $E$, in the caudate nucleus and putamen) there were immunoreactive neurons in which reaction product extended out into primary and secondary dendrites, and there were highly immunoreactive axons visible in the striatum and in a number of other regions as well (for example, in parts of the subthalamus and mesodiencephalic border zone; (see Fig. 6). In several brains we tried to enhance the immunohistochemical staining of axons and dendrites in the nucleus reticularis by preincubating the sections in $2 \%$ Triton X-100 and then incubating them by Pickel's method in hypertonic solutions containing $0.5 \mathrm{M}$ Tris-saline (Pickel et al., 1975, 1976). Despite an apparent increase in PAP staining of fibers in the striatum and elsewhere, this treatment did not result in immunoreactive staining of more than oc- casional axons either in the nucleus reticularis itself or in the dorsal thalamic nuclei to which the nucleus reticularis projects.

Figure 5 illustrates the general distribution of somatostatin-like immunoreactivity at midbrain and thalamic levels in the cat. The chartings were prepared from sections processed by the standard PAP method $(0.2 \%$ Triton X-100). It is important to note, first, that there was no sign of provincialization of the immunoreactivity within the nucleus reticularis itself. Reactive neurons appeared at all anteroposterior levels of the nucleus and in all dorsoventral positions including its swollen ventral wing (see Fig. $5 B$ ). In sharp contrast, immunoreactivity was virtually absent in neurons of adjoining cell groups. This was true both for the dorsal thalamic nuclei, where somatostatin-positive processes appeared only along the midline, and for most of the ventral thalamic derivatives as well: immunoreactive neurons did not occur in the ventral nucleus of the lateral geniculate body or, except occasionally, in its perigeniculate wing along the dorsal margin of the main geniculate's lamina A; nor did it occur in the subthalamic nucleus, nucleus campi Foreli, or most of the zona incerta. However, thin streams of immuno-
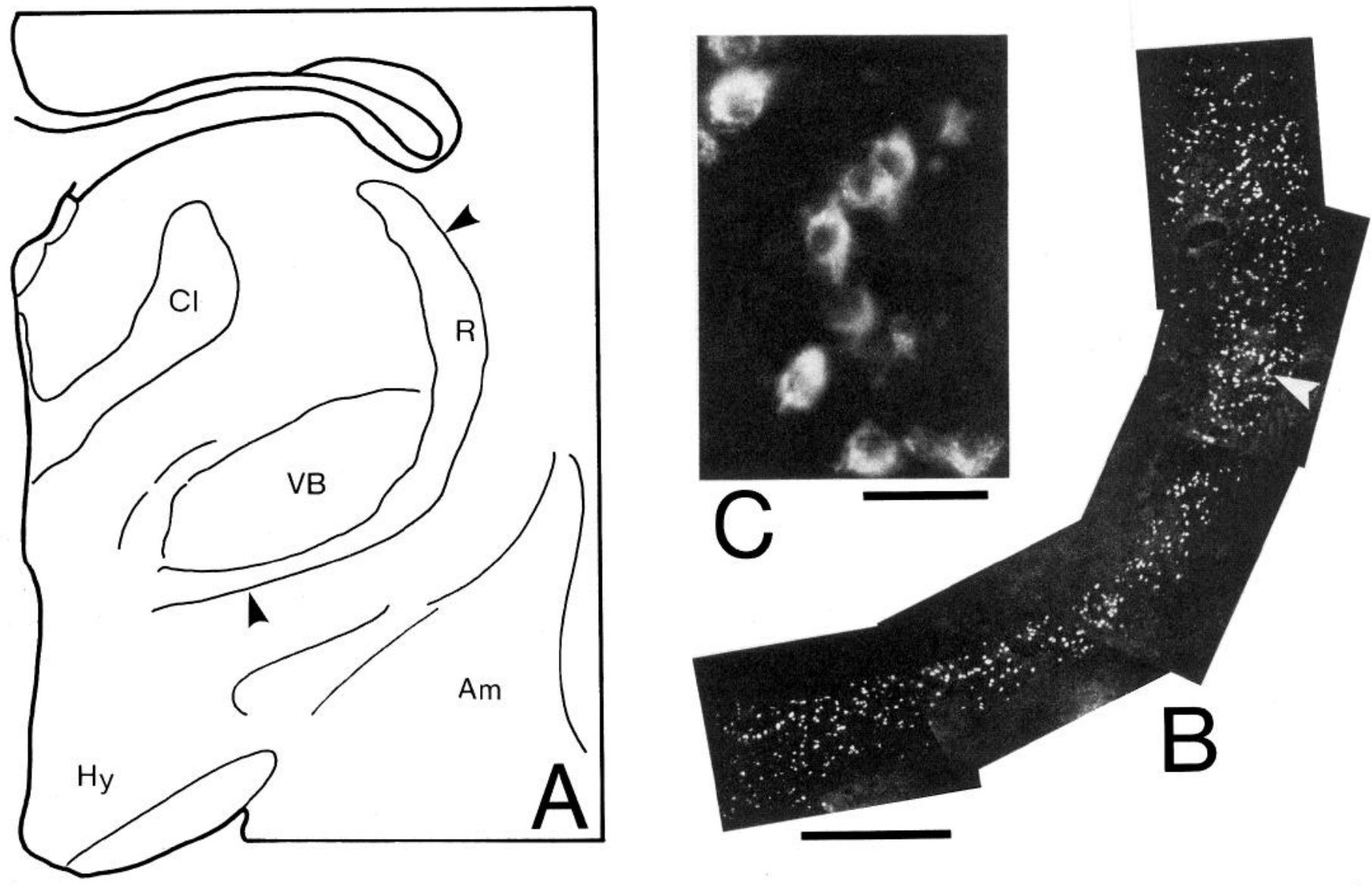

Figure 1. Distribution of immunofluorescent neurons in the nucleus reticularis thalami in a transverse section processed by the FITC method for somatostatin-like immunoreactivity using antiserum R176 directed against somatostatin-14. From the brain of a 28-day-old kitten. $A$, Outline drawing of the section showing, between arrowheads, the region for which the photomontage in $B$ was made. $C l$, nucleus centralis lateralis; $V B$, ventrobasal complex; $R$, nucleus reticularis thalami; $H y$, hypothalamus; $A m$, amygdaloid complex. $B$, Photomontage in which the immunofluorescent neurons appear pale in photographs taken under incident fluorescent light (Leitz K2 filter block). Scale marker, $1 \mathrm{~mm}$. C, Photograph taken at higher magnification illustrating immunoreactive neurons in the region indicated by the arrowhead in B. Scale marker, $50 \mu \mathrm{m}$. 

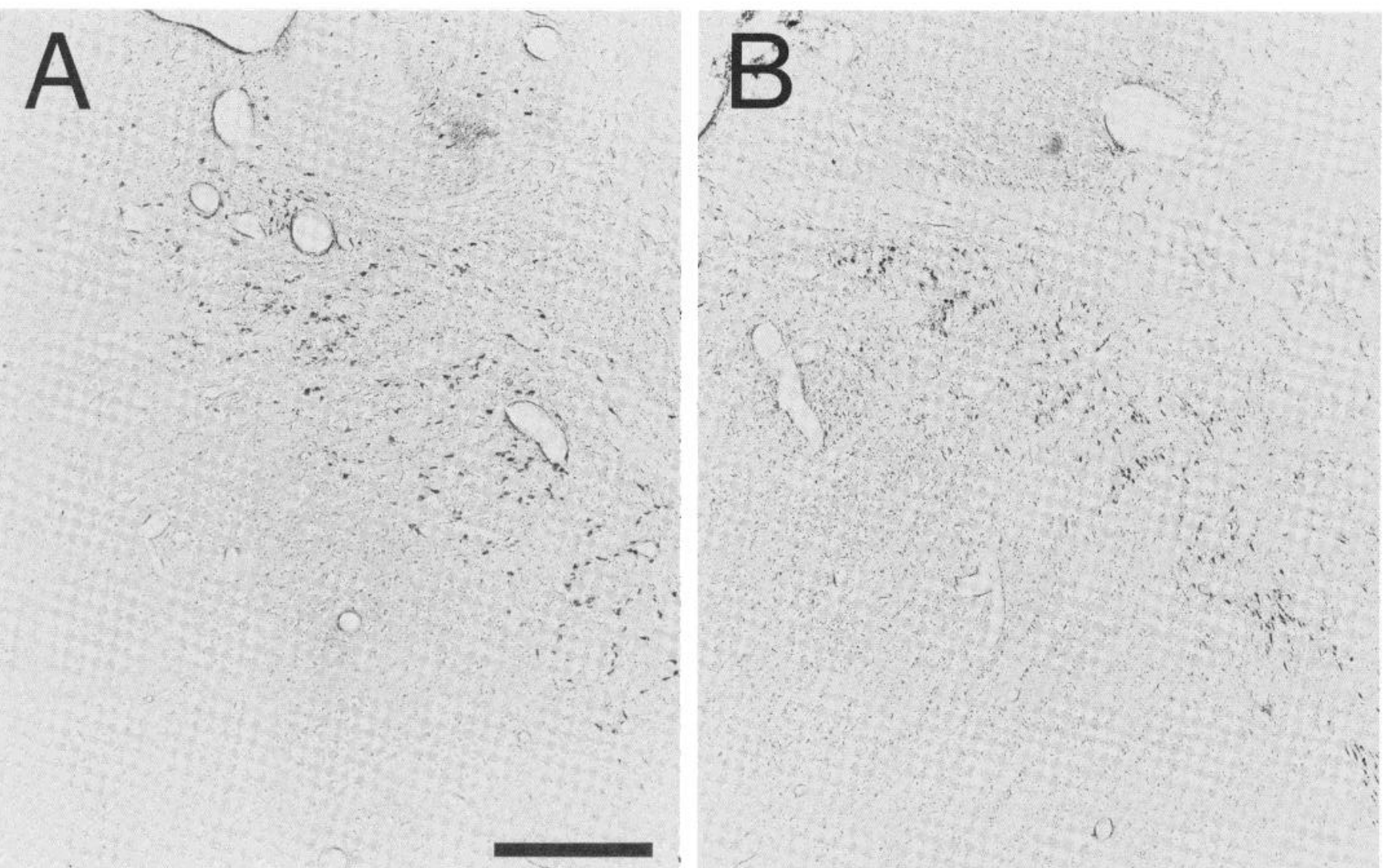

Figure 2. Light-field photographs of somatostatin-like immunoreactivity in neurons in the nucleus reticularis thalami of the cat and monkey (antiserum R176 directed against somatostatin-14). A, Transverse section through the brain of an adult cat, processed by Sternberger's PAP method. Immunoreactive neurons appear dark. Note the absence of immunoreactive neurons in thalamic nuclei of the dorsal thalamus and the presence of somatostatin-positive neurons in the body of the caudate nucleus (top, right). $B$, Transverse section through the nucleus reticularis of a rhesus macaque monkey processed for somatostatin-like immunoreactivity by the PAP method. As in the cat, reactive neurons appear in clusters in the primate nucleus reticularis and neurons in adjoining dorsal thalamic nuclei are negative. The scale marker indicates $500 \mu \mathrm{m}$ for both $A$ and $B$.

reactive cell bodies and fibers could be followed medially and caudally from a position beside the ventral part of the nucleus reticularis into the $\mathrm{H}$ fields of Forel, so that there was not everywhere abrupt discontinuity between the nucleus reticularis proper and the subthalamic region. At rostral levels (Fig. 5) these immunoreactive fibers and neurons followed a gentle sweep toward the hypothalamus and midline cell groups, which also contained intensely immunoreactive cell bodies and processes. At caudal levels there were scattered somatostatin-positive cell bodies in the ventral part of the transition zone between the subthalamus and midbrain tegmentum. These could be traced caudally, always in small numbers, in positions just beside and dorsal to the subthalamic nucleus and, still farther caudally, just dorsal to the substantia nigra.

At levels through the anterior half of the substantia nigra (Fig. 5, $D$ and $E$ ) dense somatostatin-like immunoreactivity sharply defined a wedge of tegmentum, apparently corresponding to the peripeduncular nucleus (Jones and Burton, 1976; Jones et al., 1976) and, at least in part, to Rioch's pars caudalis of the zona incerta and his nucleus lateralis tegmenti (Rioch, 1929). This region lay dorsal to the substantia nigra, lateral to the red nucleus, and caudal to the center median-parafascicular complex. The wedge of immunoreactivity had a clearly defined dorsal limit. In fact, its border with the thalamus was easy to find, even by scanning under oil immersion, because the tegmentum was crowded with somatostatinpositive processes, whereas the thalamic neuropil was nearly devoid of immunoreactivity. The lateral part of the wedge contained an extremely dense bundle of immunoreactive fibers. These fibers could be traced in a position overlying the lateral part of the substantia nigra throughout its caudal extent.

A second prominent zone of immunoreactivity appeared at the dorsal limit of the subthalamus just lateral to the descending fibers of the fasciculus retroflexus (Figs. $5 C$ and 6, $A$ to $C$ ). Judging from its position, this discrete wing-shaped region corresponds to the subparafascicular nucleus of Rioch (1929). In adjacent sections stained for acetylcholinesterase, this nucleus appeared as a zone of medium tint directly ventral to the darkly stained center median-parafascicular complex (Fig. 6A). Many of the somatostatin-positive fibers in the subparafascicular nucleus had prominent varicosities (Fig. $6 \mathrm{C}$ ) 
and some appeared to twine themselves around unreactive cell bodies at the medial edge of the immunoreactive zone. It seems probable that at least some of these immunoreactive fibers joined the main laterally placed bundles in the subthalamic-mesencephalic tegmentum, but except for a few streamers it was not possible to establish continuity of the two groups.

In addition to those zones of intense immunoreactivity, an apparently separate system of very fine immunoreactive processes was present in the pars lateralis of the substantia nigra's pars reticulata (Rioch, 1929). This immunoreactive region is indicated by the cross-hatching in Figure 5, $D$ and $E$, and will be described in a separate paper (M. -F. Chesselet and A. M. Graybiel, manuscript in preparation). In sharp contrast to the pars lateralis, the large remainder of the pars reticulata, and the pars compacta as well, was unstained. No immunoreactive cell bodies were present in the substantia nigra proper, but reactive neurons and loosely grouped immunoreactive fibers appeared in the supranigral tegmentum along virtually its full mediolateral extent. Some of the large nonreactive cell bodies in this tegmental zone were encrusted with somatostatin-positive fibers and varicosities (Fig. $6 D$ ), and it was difficult to avoid the impression that the somatostatin-like immunoreactivity was singling out a major afferent system terminating in this tegmental region and an intrinsic system of somatostatin-containing neurons as well.

A smaller paramedian system of immunoreactive fibers appeared throughout the diencephalon, and at caudal levels (Fig. 5, $D$ to $F$ ) paramedian fibers could be traced from the oculomotor nucleus ventrally and in a lateral sweep under the red nucleus. Somatostatin-immunoreactive neurons appeared in the raphe proper and also, in every section, one or two and occasionally as many as ten immunoreactive cells were present on the midline within the confines of the oculomotor complex. They thus appeared to represent either neurons of the EdingerWestphal nucleus and somatic-oculomotor columns or neurons infiltrating them.

The immunoreactive cell and fiber groupings just named could be visualized in each of the cat brains studied. There was variability in the intensity of immunoreactivity from brain to brain, however, so that intense staining of neurons in the nucleus reticularis was accompanied in some brains by very dark staining of the peripeduncular and subparafascicular nuclei and the pars lateralis of the substantia nigra, whereas in other brains the stain in these regions was less intense. One marked difference was the appearance of highly discrete zones of
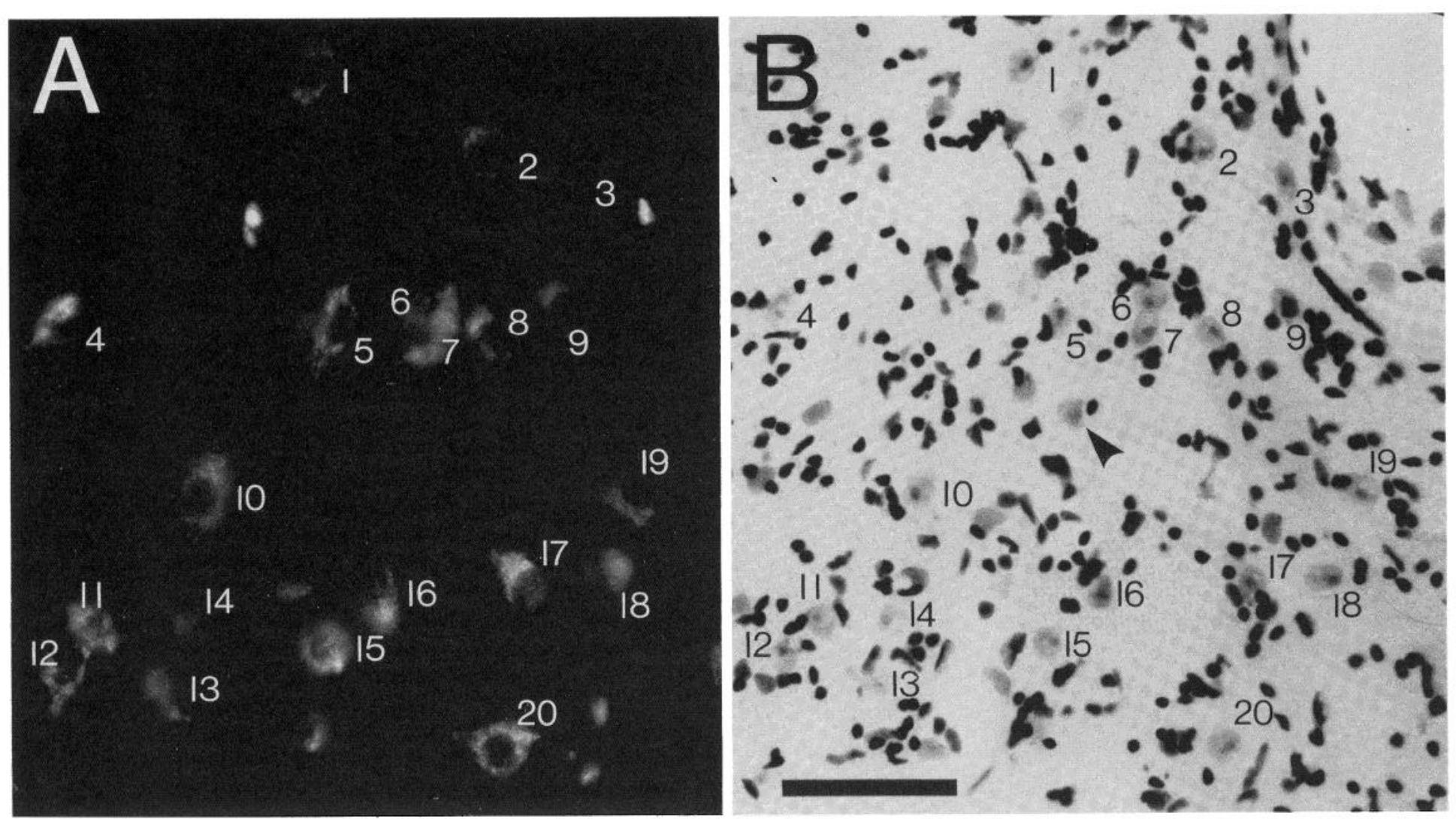

Figure 3. Matched photographs of part of nucleus reticularis thalami in a cross-section from an adult cat. The section was processed sequentially for somatostatin-like immunoreactivity $(A)$ and Nissl substance $(B)$. $A$ shows immunofluorescent neurons (pale), visible following initial processing by the FITC method after incubation with antiserum R176 directed against somatostatin14. $B$ shows the same region of the nucleus photographed after the photograph in $A$ had been made and after the section had been stained for Nissl substance. All but one of the neurons identified in $B$ by virtue of having a clearly defined nucleolus can be seen in the fluorescence photograph in $A$. The arrowhead in $B$ points to the single exception. The scale marker indicates $100 \mu \mathrm{m}$ for both $A$ and $B$. 

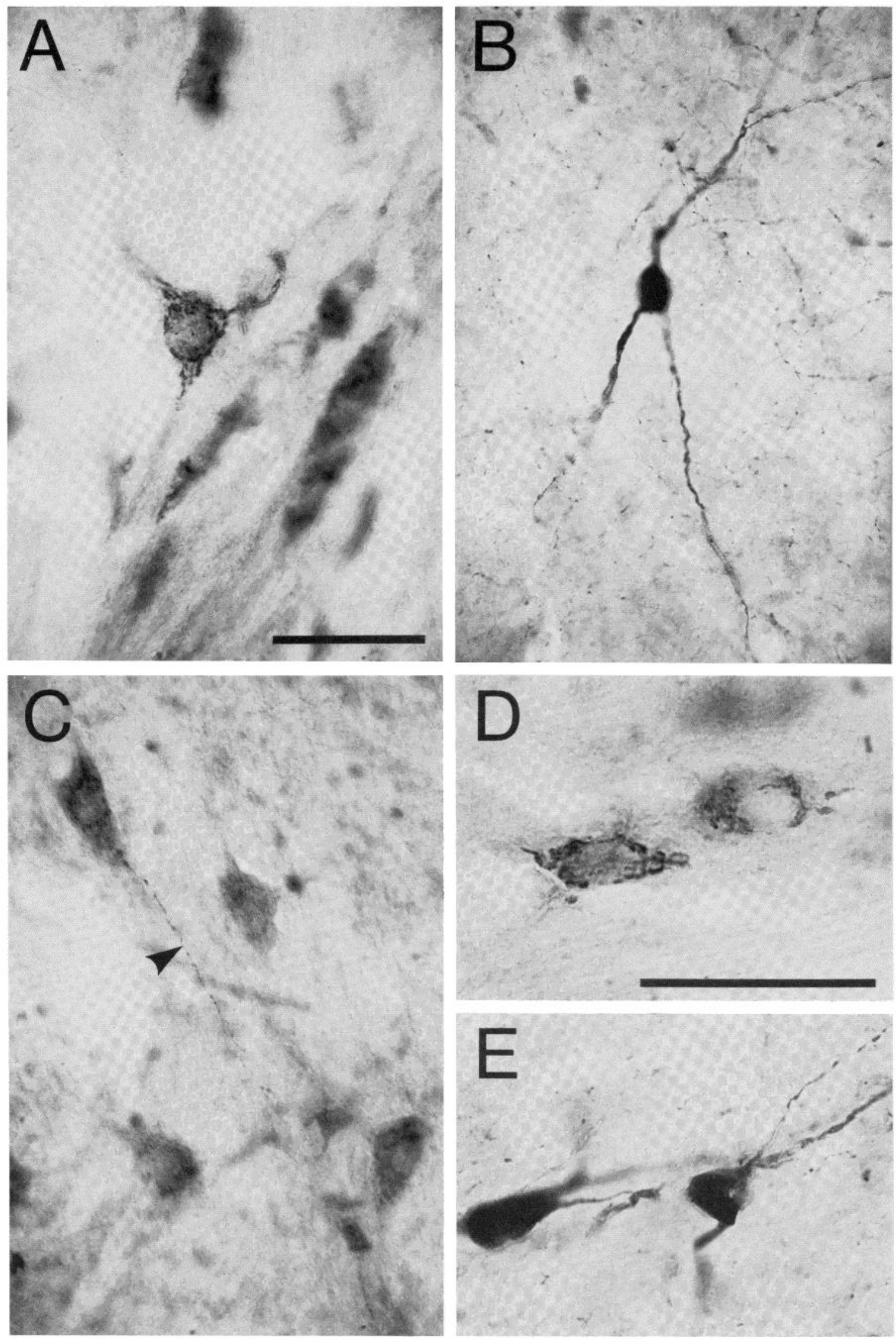

Figure 4. Typical globular appearance and perinuclear location of somatostatin-like immunoreactivity (antiserum R176 directed against somatostatin-14) visible in neurons of the nucleus reticularis in the cat $(A, C$, and $D) . C$, at the arrow, illustrates rare immunoreactive fiber in the nucleus reticularis. For comparison, $B$ and $E$ show the more extensive staining of striatal cell bodies and processes in sections incubated in the same anti-somatostatin antiserum. All photographs except that shown in $C$ illustrate neurons from a single cat. Scale markers, $50 \mu \mathrm{m} ; A$ to $C$, same magnification; $D$ and $E$, same magnification. 
immunoreactive fiber staining in the lateral habenula and in the interpeduncular nucleus in some but not all brains. The sections charted for Figure 5, for example, come from a cat in which these immunoreactive elements were scarcely visible (interpeduncular nucleus) or not visible (lateral habenula). It is not clear whether this variability resulted from slight differences in effective- ness of the tissue processing or from genuine variation in antigenic determinants from brain to brain.

In an effort to characterize more fully the immunoreactive substrate stained in the nucleus reticularis, we incubated sections from the brain of one adult cat in an antiserum directed against the part of the somatostatin28 molecule that does not contain the 14-amino acid
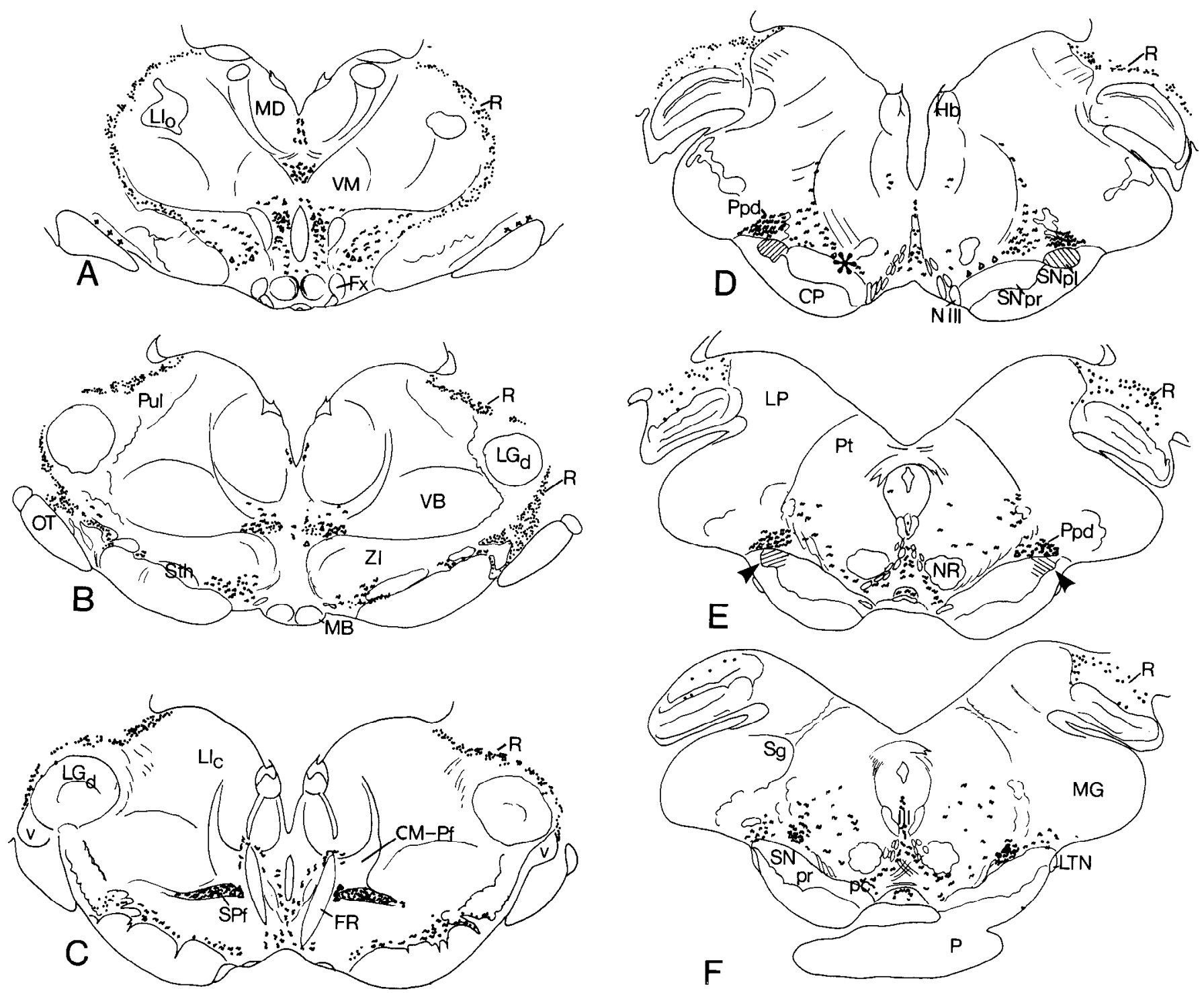

Figure 5. Schematic chartings illustrating the distribution of fibers (wavy lines) and cell bodies (solid dots) expressing somatostatin-like immunoreactivity in sections through the diencephalon and mesencephalon of an adult cat (antiserum R176 generated against somatostatin-14; PAP method). Also shown are the locations of nonreactive neurons that appear to be encrusted with immunoreactive fibers (see small, open triangles in $A, B$, and $D$ ) and a system of fine-caliber, somatostatin-immunoreactive fibers that innervate the pars lateralis of the substantia nigra (see diagonal hatching in $D$ and $E$; at arrows in $\mathrm{E}$ ). Note the dense system of immunoreactive fibers in the mesodiencephalic tegmentum (peripeduncular nucleus). The asterisk in $D$ shows the location of a neuron shown in Figure $6 D$, itself apparently nonreactive but enveloped by varicose somatostatin-positive afferent fibers. $L I_{o}$, intermediate division of lateral nucleus, pars oralis; $M D$, mediodorsal nucleus; $V M$, ventromedial nucleus; $F x$, fornix; $R$, nucleus reticularis thalami; $P u l$, pulvinar; $O T$, optic tract; $S t h$, subthalamic nucleus; $M B$, mamillary body; $Z I$, zona incerta; $V B$, ventrobasal complex; $L G_{d}$, dorsal nucleus of lateral geniculate body; $v$, ventral nucleus of lateral geniculate body; $L i_{c}$, intermediate division of lateral nucleus, pars caudalis; $S P f$, subparafascicular nucleus; $F R$, fascicularis retroflexus; $C M$ - $P f$, centermedian-parafascicular complex; Hb, habenula; $P p d$, peripeduncular nucleus; $C P$, cerebral peduncle, $N I I I$, oculomotor nerve; $S N p r$, substantia nigra, pars reticulata; $S N p l$, substantia nigra, pars lateralis; $L P$, posterior division of lateral nucleus; $P t$, pretectal region; $N R$, red nucleus; $S g$, suprageniculate nucleus; $p c$, substantia nigra, pars compacta; $P$, pons; $L T N$, lateral terminal nucleus; $M G$, medial geniculate body. 

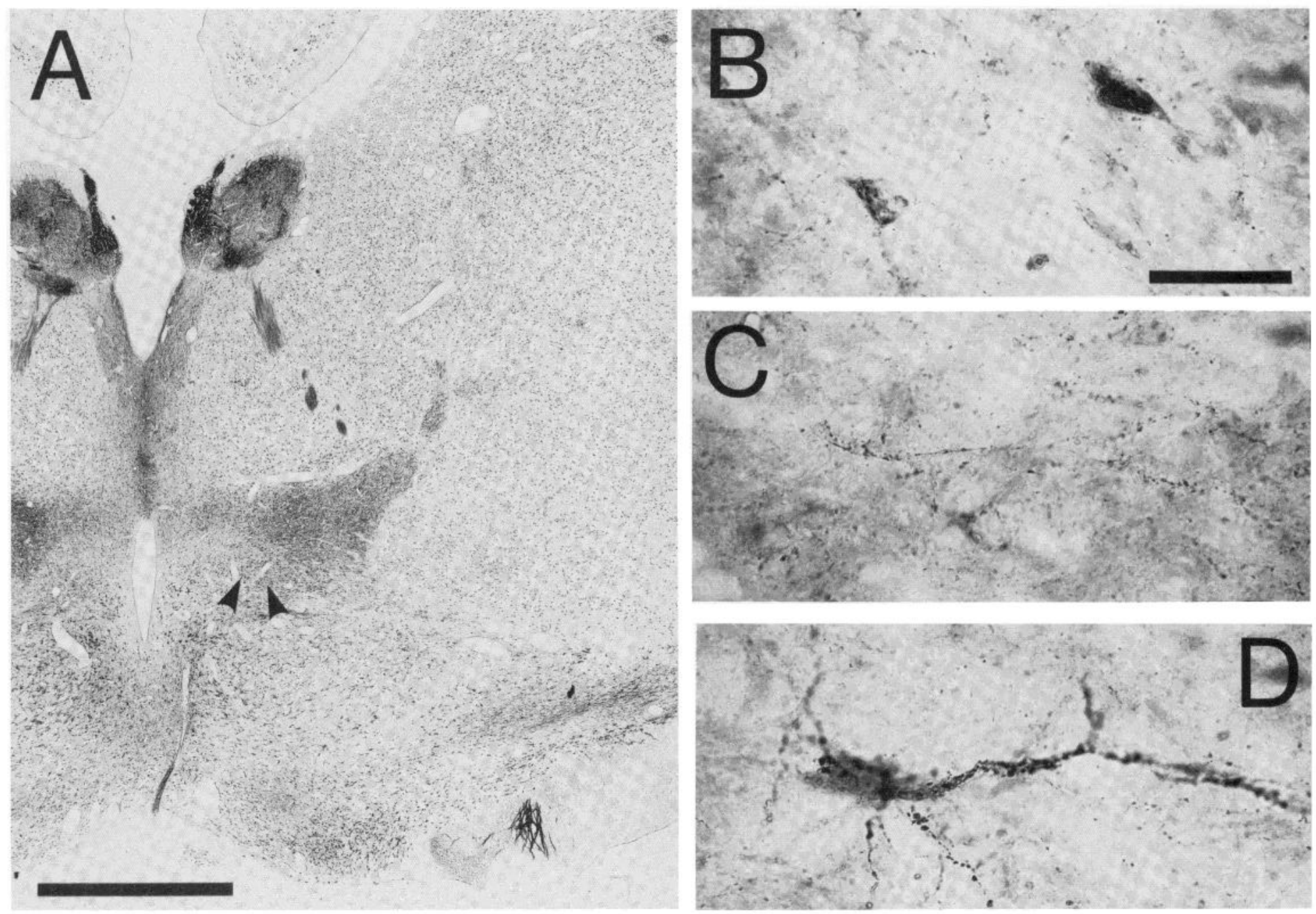

Figure 6. The subparafascicular nucleus in an acetylcholinesterase-stained section from the cat is shown at low magnification in $A$, and somatostatin (antiserum R176)-immunoreactive neurons and fibers visible in the nucleus in a serially adjoining PAP section are shown in $B$ and $C$. Arrowheads in $A$ show approximate locations of frames illustrated in $B$ (more medial) and $C$ (more lateral). The photograph in $D$ illustrates somatostatin-immunoreactive fibers in the more caudal tegmentum, apparently innervating a nonreactive neuron. The asterisk in Figure $5 D$ shows the approximate location of the neuron. Scale markers: $A$, 2 $\mathrm{mm} ; B$ to $D, 50 \mu \mathrm{m}$.

sequence of somatostatin-14. As shown in Figures 7 and $8, A$ and $C$, immunoreactivity appeared in the nucleus reticularis neurons in a pattern similar to that observed with the somatostatin-14 antiserum. A point of interest was that in sections from the same brain, neurons in the caudate nucleus also showed a perinuclear staining pattern in PAP sections incubated with the somatostatin-28 (1 to 14) antiserum (Fig. $8 B$ ), but they showed the familiar soma-and-dendrite staining pattern when incubated with the somatostatin-14 antiserum (Fig. $8 D$ ).

As an adjunct to the experiments on somatostatin, we also applied antisera against Met-enkephalin (see Graybiel et al., 1981) and against APP (see Vincent et al., 1982) to a few sections to test for the possibility that the nucleus reticularis neurons might express immunoreactivity to these other peptides. Despite intense staining of cell bodies elsewhere, including neurons of the striatum (Fig. $9 B$, inset), the nucleus reticularis was negative.
Finally, we studied the nucleus reticularis in sections stained for acetylcholinesterase and found that the neurons showed low to moderate levels of acetylcholinesterase activity both in untreated and colchicine-pretreated cats and in a cat injected with DFP $6 \mathrm{hr}$ before perfusion (Fig. 9A).

\section{Discussion}

The observation of intense somatostatin-like immunoreactivity in the thalamic reticular nucleus adds to a growing body of evidence for an extensive extrahypothalamic distribution of somatostatin-immunoreactive peptides (Hökfelt et al., 1975, 1978, 1980; Kobayashi et al., 1977; Iversen et al., 1978a, b; Finley et al., 1981; Takatsuki et al., 1981), but this finding has particular interest for three reasons.

First, the nucleus reticularis is classified on embryological grounds as a ventral thalamic derivative together 

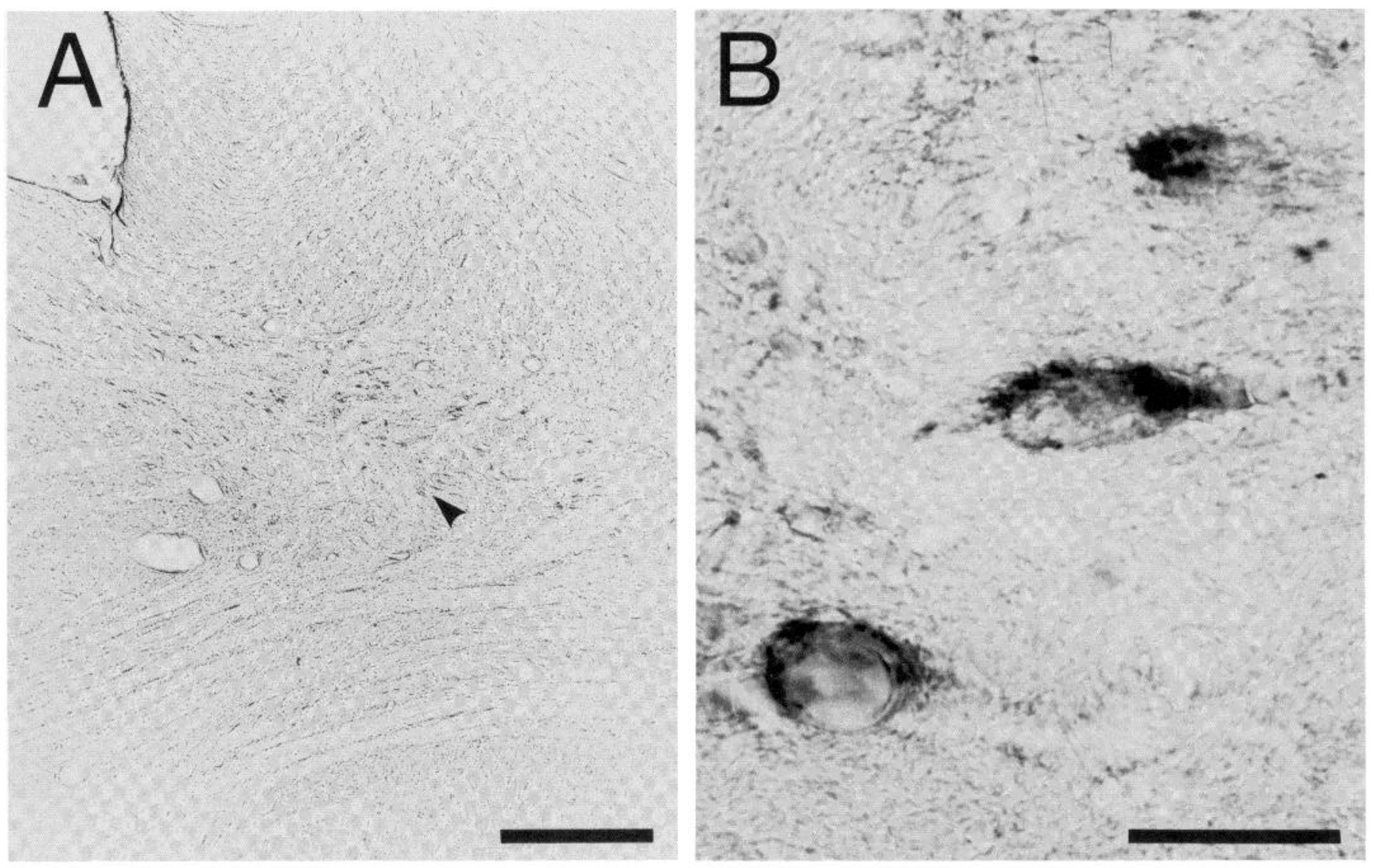

Figure 7. Photographs illustrating immunoreactive neurons of the cat's nucleus reticularis in a section incubated with the A3b antiserum directed against somatostatin-28 (1-14) (PAP method). The arrowhead in $A$ points to the location of neurons shown at higher magnification in B. Scale markers: $A, 500 \mu \mathrm{m} ; B, 50 \mu \mathrm{m}$. Compare with Figures 2, 4, and 8 .

with the ventral nucleus of the lateral geniculate body and parts of the subthalamic region including the zona incerta (but not the subthalamic nucleus) and the nuclei identified by Kuhlenbeck (1948) in the human brain as the filiform nucleus and nucleus reuniens ventralis. Our findings suggest that, by virtue of its high content of somatostatin-like immunoreactivity, the nucleus reticularis in the cat and monkey can be distinguished not only from the dorsal thalmus but also from most regions of the ventral thalamus. Of the presumed ventral thalamic derivatives studied in the cat, it was only in the subparafascicular nucleus and in the peripeduncular nucleus (the supranigral tegmentum and its rostral extension corresponding to the nucleus lateralis tegmenti and zona incerta pars caudalis of Rioch) that more than scattered somatostatin-positive neurons could be found. In the dorsal thalamus, also, scarcely any neurons possessed somatostatin-like immunoreactivity. Assuming that the immunohistochemical localizations did not reflect falsenegative results, these observations suggest that the presence of somatostatin-like immunoreactivity may be a defining characteristic of the thalamic reticular nucleus.

The immunohistochemical distinctiveness of the nucleus reticularis parallels the sharp differences between the patterns of its efferent connections and those of neighboring nuclei. The nucleus reticularis has restricted connections with the dorsal thalamus, whereas the dorsal thalamic nuclei themselves project widely to cortical and subcortical regions of the telencephalon and the zona incerta, and the ventral nucleus of the lateral geniculate body gives rise to extensive descending and intradiencephalic pathways (Edwards et al., 1974; Graybiel, 1974; Swanson et al., 1974; Ricardo, 1980, 1981). Less is known about the connections of the other somatostatin-positive zones of the mesodiencephalic tegmentum, the subparafascicular nucleus and the peripeduncular nucleus; but it is of great interest that these regions share the characteristic of projecting to the amygdaloid complex (Jones and Burton, 1976; Jones et al., 1976; Veening, 1978; Otterson and Ben-Ari, 1979; Mehler, 1980; Mehler et al., 1982). The immunohistochemical delimitation of these regions in the present study indicates that they could provide the amygdala with somatostatin-containing afferent fibers and further suggests that they may themselves receive afferents containing a somatostatin-like peptide. The finding that somatostatin-like immunoreactivity delimits the pars lateralis of the substantia nigra makes it likely that this region, aiso, receives afferent connections distinct from those of the adjoining nigral subdivisions.

In terms of the embryologic origins of the diencephalon, the present study raises the possibility that somatostatin-like immunoreactivity could provide a specific developmental marker for subsets of developing neurons 

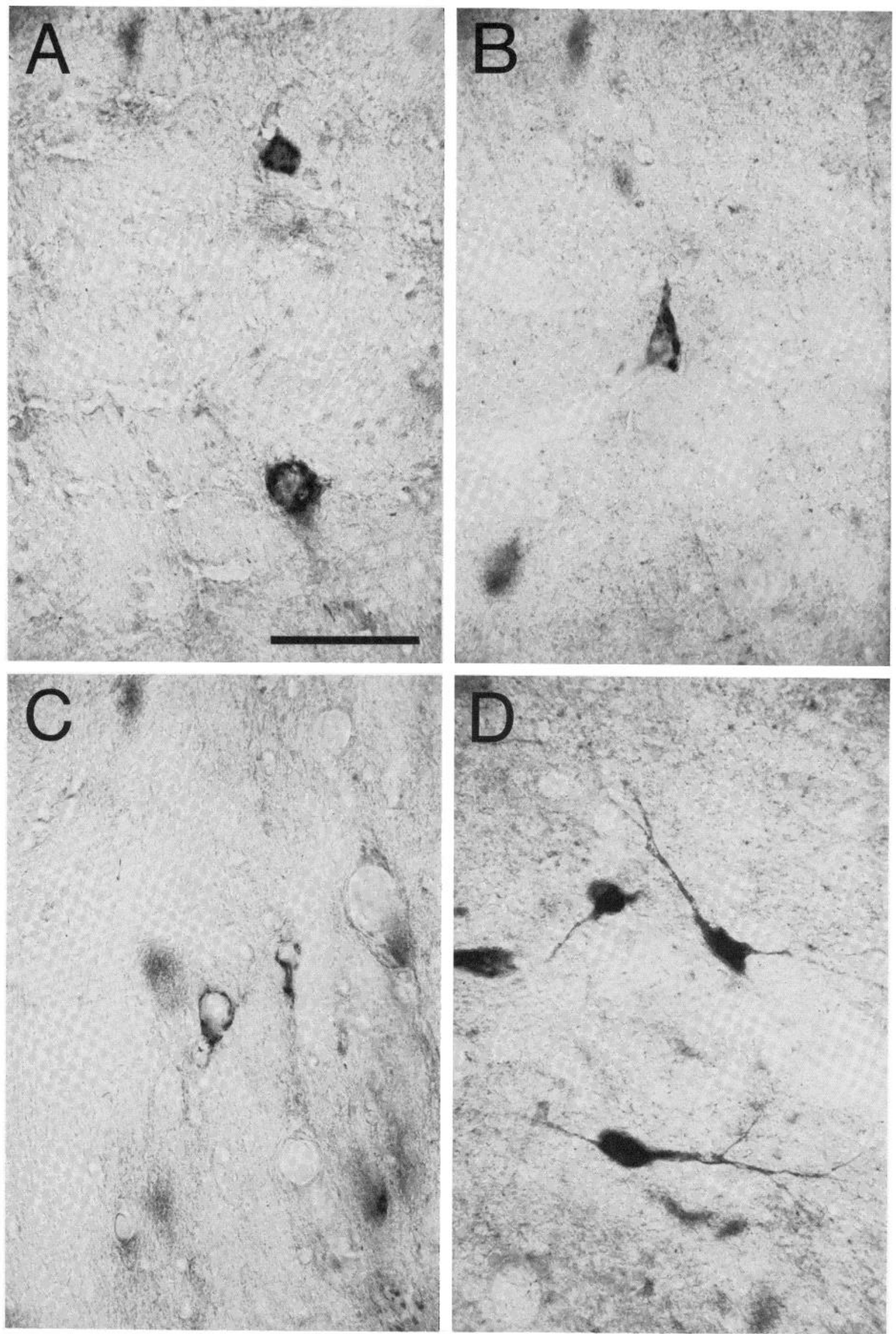

Figure 8. The photomicrographs in $A$ and $C$ illustrate the similarity in the pattern of somatostatin-like immunoreactivity in nucleus reticularis neurons from sections incubated with $(A)$ anti-somatostatin-28 (1-14) serum A3b and $(C)$ anti-somatostatin14 serum R176. $B$ and $D$ illustrate the different patterns observed with these two antisera in the caudate nucleus. $B$, Striatal neuron showing immunoreactivity to the somatostatin-28 (1-14) antiserum; $D$, striatal neuron showing immunoreactivity to the somatostatin-14 antiserum. All photographs illustrate neurons from the same cat, an adult animal that had received an intrastriatal injection of colchicine $(800 \mu \mathrm{g})$ on the contralateral side. Scale marker, $50 \mu \mathrm{m}$. 

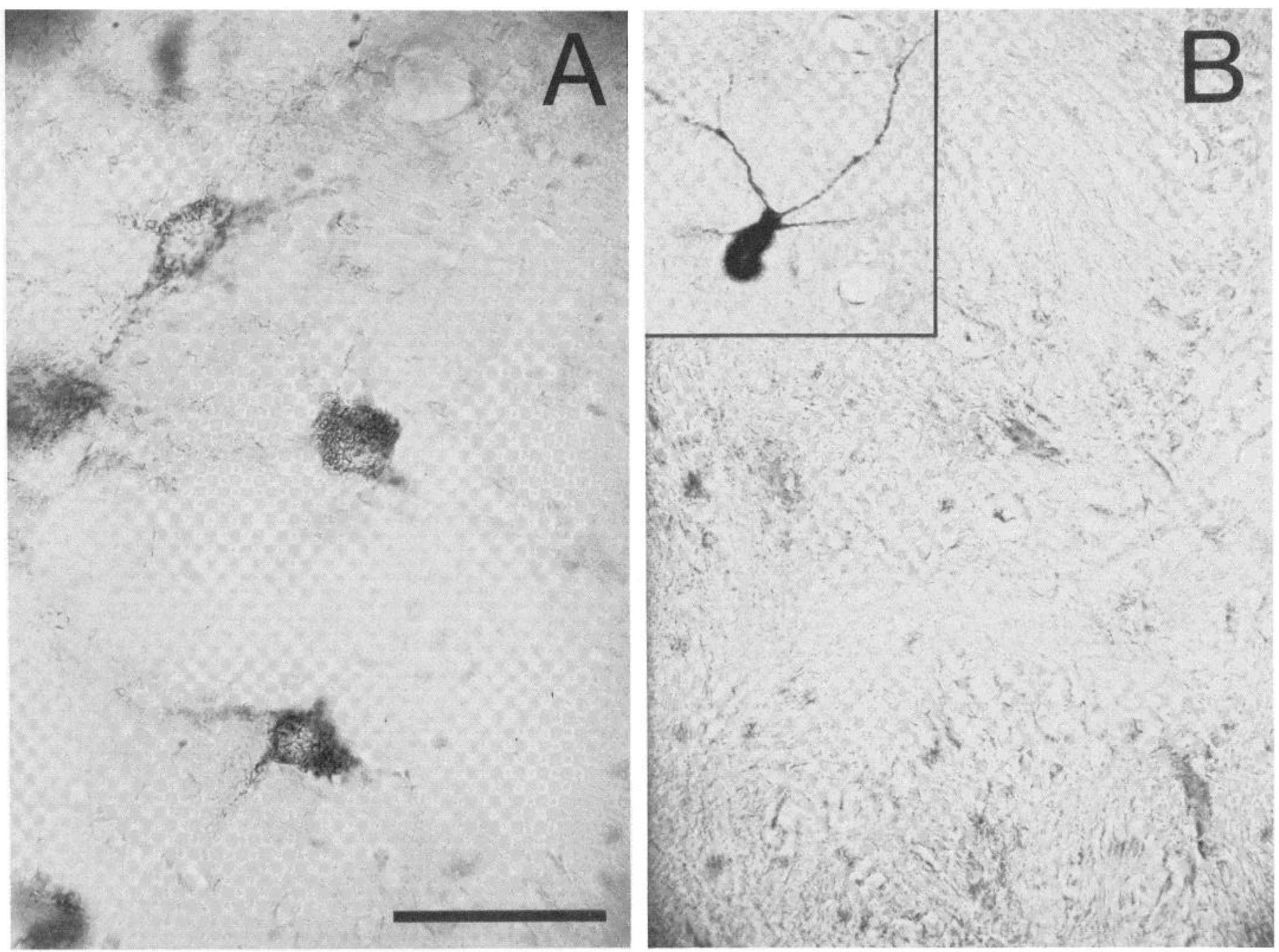

Figure 9. A illustrates acetylcholinesterase-positive neurons in the nucleus reticularis from a cat pretreated with DFP 6 hr before perfusion. $B$ illustrates, in another adult cat, the lack of immunoreactivity to APP antiserum of neurons in the nucleus reticularis despite the presence of APP-like immunoreactivity in neurons elsewhere in the same and adjoining sections (the inset in $B$, for example, illustrates APP-like immunoreactivity in a striatal neuron from the caudate nucleus). Scale marker, $50 \mu \mathrm{m}$ for all photographs.

destined to inhabit the nucleus reticularis and restricted regions of the subthalamus and mesodiencephalic tegmentum. It would be valuable to pursue this possibility by combining a $\left[{ }^{3} \mathrm{H}\right]$ thymidine study of the time of origin of diencephalic neurons with immunohistochemical localization of somatostatin-related peptides in the same brains. It is not known how early immunoreactivity to these peptides is expressed in the cat brain, but in the rat, sharp changes in the distribution of somatostatinlike immunoreactivity have been noted during ontogeny (Lechan et al., 1980; Shiosaka et al., 1982).

A second point of interest in the present study is that despite the intense immunoreactivity of cell bodies in the nucleus reticularis, the reaction product was localized mainly to the perinuclear region. We were therefore unable to visualize the dendritic arbors and axon collaterals of these cells, and we found only rare hints in the somatostatin sections of the dense innervation of the adjoining dorsal thalamic nuclei provided by the nucleus reticularis. This restricted perikaryal localization of the reaction product was all the more remarkable in view of the intense immunoreactivity of axons in the adjoining mesodiencephalic tegmentum and more complete filling of the perikaryal and dendritic cytoplasm of nearby neurons in the striatum and elsewhere. A similar predominantly perinuclear location of somatostatin-like immunoreactivity in certain regions of the rat's central and peripheral nervous systems led Johansson (1978) to suggest that the reaction product is restricted to the Golgi apparatus, and that this localization of somatostatin-like immunoreactivity may reflect the presence of a large precursor molecule or prohormone of somatostatin. In the accompanying paper (Oertel et al., 1983) the preferential distribution of immunoreactivity in the Golgi apparatus is confirmed for the nucleus reticularis in electron microscopic observations on sections prepared with the same antisera against the 14-amino acid form of somatostatin used in the present study (R176C, R176D).

Although immunoreactivity was not observed in neurons of the nucleus reticularis when control sections were 
incubated in R176 antiserum that had been preabsorbed by the addition of excess synthetic somatostatin (nor when the antiserum was omitted altogether or diluted to 1:10,000), we could not, by the use of the R176 antisera, adequately differentiate among different molecular species having somatostatin-like immunoreactivity (for example, the 12,000-, 4,000-, and 2,000-dalton forms of Spciss and Vale, 1980; see also Noe et al., 1981). Therefore, it was not clear whether the restricted cellular localization of somatostatin-like immunoreactivity in the nucleus reticularis indicates that these neurons mainly contain a particular species of somatostatin-immunoreactive molecule (presumably one of the higher weight precursor forms as Johansson (1978) suggested) or that the biosynthesis of the form of somatostatin in the reticularis axons and terminals occurs slowly or is under a regulatory system different from that of neurons in which immunoreactive processes were clearly visible. It was for this reason that we made a preliminary study with an antiserum (A3b) directed against the non-somatostatin (1 to 14) sequence of somatostatin-28. The fact that the neurons of the nucleus reticularis were immunoreactive under these conditions suggests that they either contain both somatostatin-28 and somatostatin-14 or they contain a prosomatostatin molecule that could serve as a precursor for these peptides.

In relation to this possibility, it is of particular interest to emphasize the contrast, seen in sections incubated with the R176 (somatostatin-14) antisera, between the restricted perikaryal distribution of somatostatin-like immunoreactivity in neurons of the nucleus reticularis and the more extensive distribution of immunoreactive staining of neurons in the striatum. Neurons of the nucleus reticularis are noted for their high firing rates and bursting activity rhythms (Schlag and Waszah, 1971), whereas most neurons recorded in the striatum are characterized by low rates of firing (Buchwald et al., 1973; Sugimori et al., 1978). The patterns of immunoreactivity observed in these regions do not necessarily bear directly on whether release of somatostatin occurs at terminals of their constituent neurons, but if somatostatin does in fact act as a neurotransmitter or neuromodulator in these regions, the physiological activity of the neurons could be expected to influence the rate of its synthesis and turnover and, as a result, its visibility in cell bodies and terminals of histochemically treated sections (see, e.g., Reichlin, 1980). Recordings from known somatostatin-containing neurons and further immunohistochemistry with antisera specific for particular forms of somatostatin would be of great value, as would be a parallel study of the distribution of somatostatin receptors in these nuclei (Reubi et al., 1981; Srikant and Patel, 1981). The preliminary findings reported here already suggest that with the anti-somatostatin-28 ( 1 to 14 ) antiserum, the striatal neurons show a restricted perinuclear pattern of immunoreactivity instead of the more extensive staining typical in sections processed with the anti-somatostatin-14 antiserum. This suggests that these neurons, like nucleus reticularis neurons, might contain a prosomatostatin, or at least both somatostatin-28 and somatostatin-14. One possible mechanism to account for the different immunohistochemical staining properties of these two sets of cells is that low firing rates of the striatal cells could allow buildup of the smaller molecule, but high firing rates of reticularis neurons would lead to the using up of the smaller molecule as soon as it is produced. It would clearly be of great interest to study the immunoreactivity of these neurons fixed under different conditions of activity.

The third observation we wish to stress is that in each brain, all or nearly all of the neurons of the nucleus reticularis seemed to express somatostatin-like immunoreactivity. This implies a certain uniformity in the neurochemistry of the nucleus despite its subdivision into zones interconnected with different parts of the thalamus and neocortex. Moreover, because neurons in the nucleus reticularis have been shown to contain the enzymes acetylcholinesterase (see Fig. 9A) and GAD (see Houser et al., 1980; Oertel et al., 1983), our observations also raised the possibility that somatostatin in the nucleus reticularis coexists with one or more neurotransmitters (cf. Hökfelt et al., 1977, 1980; Vincent et al., 1982). The accompanying paper (Oertel et al., 1983) reports experiments which directly demonstrate that somatostatin and GAD do coexist in the reticularis neurons. The functional significance of the observations described here may thus, in part, lie in the effects of somatostatin on GABAmediated inhibitions.

In the present study we further tested neurons of the nucleus reticularis for co-occurrence of somatostatin with two other neuropeptides. The first of these, antigenically related to APP, is known to coexist with somatostatin in neurons of the striatum and other regions (Vincent et al., 1982; M. -F. Chesselet and A. M. Graybiel, manuscript in preparation), but we were unable to demonstrate APPlike immunoreactivity in the nucleus reticularis. Nor could we demonstrate co-occurrence with the second peptide, Met-enkephalin, despite the fact that immunoreactivity to Met-enkephalin was visible in neurons of the ventral nucleus of the lateral geniculate body immediately adjoining the nucleus reticularis (A. M. Graybiel, N. Brecha, and H. K. Karten, manuscript in preparation).

Although these tests for co-localization of peptides were negative, acetylcholinesterase could be demonstrated in most neurons of the nucleus reticularis in cats pretreated with DFP or colchicine and in some cats without such pretreatments. The presence of acetylcholinesterase is by no means easy to interpret in functional terms, however, because unlike the GAD, which almost certainly is acting on glutamic acid to produce GABA, the substrate for the acetylcholinesterase is uncertain (cf. Lundberg et al., 1979). On the one hand, although acetylcholinesterase is the degradative enzyme of the cholinergic mechanism, it is not a universal marker for neurons containing acetylcholine (see, e.g., Silver, 1974), and there is no strong evidence for acetylcholine being released by nucleus reticularis neurons or for choline acetyltransferase being present in them (Kimura et al., 1981; A. M. Graybiel, M. -F. Chesselet, and F. Eckenstein, unpublished observations). On the other hand, although acetylcholinesterase has been shown in biochemical studies to have peptidase activity (Chubb et al., 1980), its hydrolytic activity has been demonstrated only for substance $P$ and Met- and Ieu-enkephalin, and no such activity has been found in tests with somatostatin (Chubb et al., 1980, 1982). It is interesting, nevertheless, that the presence of 
acetylcholinesterase (or butyrylcholinesterase) is one of the principal histochemical characteristics of cells in the so-called APUD (amine and precursor uptake and decarboxylation) series defined by Pearse $(1968,1969)$ as peptide-secreting cells that contain a biogenic amine, take up its precursor, and contain an amino acid decarboxylase. Coexistence of somatostatin, acetylcholinesterase, and GABA (the last being an amino acid that is synthesized in a decarboxylation step by GAD) could thus represent an extension of the APDU series.

\section{References}

Arimura, A., G. Lundqvist, J. Rothman, R. Chang, R. Fernandez-Durango, R. P. Elde, D. H. Coy, C. Meyers, and A. V. Schally (1978) Radioimmunoassay of somatostatin. Metabolism 27 (Suppl. 1): 1139-1144.

Buchwald, N. A., D. D. Price, L. Vernon, and C. C. Hull (1973) Caudate intracellular responses to thalamic and cortical inputs. Exp. Neurol. 38: 311-323.

Chubb, I. W., A. J. Hodgson, and G. H. White (1980) Acetylcholinesterase hydrolyzes substance P. Neuroscience 5: 20652072.

Chubb, I. W., E. Ranieri, A. J.Hodgson, and G. H. White (1982) The hydrolysis of leu- and met-enkephalin by acetylcholinesterase. Neurosci. Lett. Suppl. 8: S39.

Coons, A. H. (1958) Fluorescent antibody methods. In General Cytochemical Methods, J. F. Danielli Ed., pp. 399-422, Academic Press, Inc., New York.

Edwards, B., A. C. Rosenquist, and L. A. Palmer (1974) An autoradiographic study of ventral lateral geniculate projections in the cat. Brain Res. 72: 282-287.

Elde, R. P., and J. A. Parsons (1975) Immunocytochemical localization of somatostatin in cell bodies of the rat hypothalamus. Am. J. Anat. 144: 541-548.

Filion, M., Y. Lamarre, and J. P. Cordeau (1969) Activités unitaires du noyau ventralis lateralis du thalamus au cours de la veille et du sommeil. J. Physiol. (Paris) 61 (Suppl. 2): 290

Finley, J. C. W., J. L. Maderdrut, L. J. Roger, and P. Petrusz (1981) The immunocytochemical localization of somatostatin-containing neurons in the rat central nervous system. Neuroscience 6: 2173-2192.

Frigyesi, T. L., and R. Schwartz (1972) Cortical control of thalamic sensorimotor relay activities in the cat and the squirrel monkey. In Corticothalamic Projections and Sensorimotor Activities, T. L. Frigyesi, E. Rinvik, and M. D. Yahr, eds., pp. 161-195, Raven Press, New York.

Graham, R. C., Jr., and M. J. Karnovsky (1966) The early stages of absorption of injected horseradish peroxidase in the proximal tubules of mouse kidney: Ultrastructural cytochemistry by a new technique. J. Histochem. Cytochem. 14: 291302 .

Graybiel, A. M. (1974) Visuo-cerebellar and cerebello-visual connections involving the ventral lateral geniculate nucleus. Exp. Brain Res. 20: 303-306.

Graybiel, A. M., and D. M. Berson (1980) Histochemical identification and afferent connections of subdivisions in the lateralis-posterior-pulvinar complex and related thalamic nuclei in the cat. Neuroscience 5: 1175-1238.

Graybiel, A. M., C. W. Ragsdale, E. S. Yoneoka, and R. P. Elde (1981) An immunohistochemical study of enkephalins and other neuropeptides in the striatum of the cat with evidence that the opiate peptides are arranged to form mosaic patterns in register with the striosomal compartments visible by acetylcholinesterase staining. Neuroscience 6: 377-397.

Hökfelt, T., R. Elde, O. Johansson, R. Luft, and A. Arimura (1975) Immunohistochemical evidence for the presence of somatostatin, a powerful inhibitory peptide, in some primary sensory neurons. Neurosci. Lett. 1: 231-235.

Hökfelt, T., L. -G. Elfvin, R. Elde, M. Schultzberg, M. Goldstein, and R. Luft (1977) Occurrence of somatostatin-like immunoreactivity in some peripheral sympathetic noradrenergic neurons. Proc. Natl. Acad. Sci. U. S. A. 74: 3587-3591.

Hökfelt, T., R. Elde, O. Johansson, A. Ljungdahl, M. Schultzberg, K. Fuxe, M. Goldstein, G. Nilsson, B. Pernow, L. Terenius, D. Ganten, S. L. Jeffcoate, J. Reheld, and S. Said (1978) Distribution of peptide-containing neurons. In Psychopharmacology: A Generation of Progress, M. A. Lipton, A. DiMascio, and K. F. Killiam, eds., pp. 39-66, Raven Press, New York.

Hökfelt, T., O. Johansson, A. Ljungdahl, J. M. Lundberg, and M. Schultzberg (1980) Peptidergic neurons. Nature 284: 515521.

Houser, C. R., J. F. Vaughn, R. P. Barber, and E. Roberts (1980) GABA neurons are the major type of the nucleus reticularis thalamis. Brain Res. 200: 341-354.

Iversen, L.L., S. D. Iversen, F. Bloom, C. Douglas, M. Brown, and W. Yale (1978a) Calcium-dependent release of somatostatin and neurotensin from rat brain in vitro. Nature 273 : 161-163.

Iversen, L. L., R. A. Nicoll, and W. W. Vale (1978b) Neurobiology of peptides. Neurosci. Res. Proj. Bull. 16: 211-370.

Johansson, O. (1978) Localization of somatostatin-like immunoreactivity in the Golgi apparatus of central and peripheral neurons. Histochemistry 58: 167-176.

Jones, E. G. (1975) Some aspects of the organization of the thalamic reticular complex. J. Comp. Neurol. 162: 285-308.

Jones, E. G., and H. Burton (1976) A projection from the medial pulvinar to the amygdala in primates. Brain Res. 104: 142147.

Jones, E. G., H. Burton, C. B. Saper, and L. W. Swanson (1976) Midbrain, diencephalic and cortical relationships of the basal nucleus of Meynert and associated structures in primates. J. Comp. Neurol. 167: 385-420.

Kimura, H., P. L. McGeer, J. H. Peng, and E. G. McGeer (1981) The central cholinergic system studied by choline acetyltransferase immunohistochemistry in the cat. J. Comp. Neurol. 200: 151-201.

Kobayashi, R., M. Brown, and W. Vale (1977) Regional distribution of neurotensin and somatostatin in rat brain. Brain Res. 126: 584-588.

Kublenbeck, $H$. (1948) The derivatives of the thalamus ventralis in the human brain and their relation to the so-called subthalamus. Milit. Surgeon 102: 443-447.

Larsson, L. -I. (1981) A novel immunocytochemical model system for specificity and sensitivity screening of antisera against multiple antigens. J. Histochem. Cytochem. 29: 408410.

Lechan, R. M., J. L. Nestler, R. J. Robbins, S. Jacobson, and J. Bollinger (1980) Ontogenesis of somatostatin (SRIF) in the forebrain of the rat central nervous system. Soc. Neurosci. Abstr. 4: 354 .

Lundberg, J. M., T. Hokfelt, M. Schultzberg, K. Uvnas-Wallensten, C. Kohler, and S. I. Said (1979) Occurrence of vasoactive intestinal polypeptide (VIP)-like immunoreactivity in cholinergic neurons of the cat: Evidence from combined immunohistochemistry and acetylcholinesterase staining. Neuroscience 4: 1439-1559.

Mehler, W. R. (1980) Subcortical afferent connections of the amygdala in the monkey. J. Comp. Neurol. 190: 733-762.

Mehler, W. R., J. K. Pretarius, K. D. Phelan, and P. W. Mantyh (1981) Diencephalic afferent connections of the amygdala in the squirrel monkey with observations and comments on the cat and rat. INSERM Symp. 20: 105-120.

Montero, V. M., R. W. Guillery, and C. N. Woolsey (1977) Retinotopic organization within the thalamic reticular nucleus. Brain Res. 138: 407-421. 
Noe, B. D., D. J. Fletcher, and G. E. Bauer (1981) Biosynthesis of glucagon and somatostatin. In The Iselts of Langerhans, S. J. Cooperstein and D. Watkins eds., pp. 189-224, Academic Press, Inc., New York.

Oertel, W. H., A. M. Graybiel, E. Mugnaini, R. P. Elde, D. E. Schmechel, and I. J. Kopin (1983) Coexistence of glutamic acid decarboxylase- and somatostatin-like immunoreactivity in neurons of the feline nucleus reticularis thalami. J. Neurosci. 3: 1322-1332.

Otterson, O. P. and Y. Ben-Ari (1979) Afferent connections to the amygdaloid complex of the rat and cat. J. Comp. Neurol. 187: 401-424.

Pearse, A. G. E. (1968) Common cytochemical and ultrastructural characteristics of cells producing polypeptides (the APUD Series) and their relevance to thyroid and ultimobranchial C cells and calcitonin. Proc. R. Soc. Lond. (Biol.) 170: $71-80$

Pearse, A. G. E. (1969) The cytochemistry and ultrastructure of polypeptide hormone-producing cells of the APUD series and the embryologic, physiologic and pathologic implications of the concept. J. Histochem. Cytochem. 17: 303-313.

Pickel, V. M., T. H. Joh, and D. J. Reis (1975) Ultrastructural localization for tyrosine hydroxylase in noradrenergic neurons of brain. Proc. Natl. Acad. Sci. U. S. A. 72: 659-663.

Pickel, V. M., T. H. Joh, and D. J. Reis (1976) Monoaminesynthesizing enzymes in central dopaminergic, noradrenergic and serotonergic neurons. Immunocytochemical localization by light and electron microscopy. J. Histochem. Cytochem. 24: 792-806.

Purpura, D. P. (1973) Intracellular studies of synaptic organization in the mammalian brain. In Structure and Function of Synapses, G. D. Pappas and D. P. Purpura, eds., pp. $257-$ 302, Raven Press, New York.

Ramon y Cajal, S. (1911) Histologie du Systeme Nerveux de l'Homme et des Vertebres, Maroine, Paris.

Ramon y Cajal, S. (1966) Studies on the Diencephalon, E. Ramon-Moliner, transl., pp. 59-60, Charles C Thomas, Springfield, IL.

Reichlin, S. (1980) Peptides in neuroendocrine regulation. In Peptides: Integrators of Cell and Tissue Function, F. F. Bloom, ed., pp. 235-250, Raven Press, New York.

Reubi, J. -C., M. H. Perrin, J. E. Rivier, and W. Vale (1981) High affinity binding sites for a somatostatin-28 analog in rat brain. I ife Sci. 28: 2191-2198.

Ricardo, J. A. (1980) Efferent connections of the subthalamic region in the rat. I. The subthalamic nucleus of Luys. Brain Res. 202: 257-271.

Ricardo, J. A. (1981) Efferent connections of the subthalamic region in the rat. II. The zona incerta. Brain Res. 214:43-60.

Rioch, D. (1929) Studies on the diencephalon of carnivora. II. Certain nuclear configurations and fiber connections of the subthalamus and midbrain of the $\mathrm{dog}$ and cat. J. Comp. Neurol. 49: 121-153.

Scheibel, M. E., and $\Lambda$. B. Scheibel (1966) The organization of the nucleus reticularis thalami: A Golgi study. Brain Res. 1: $43-62$.

Schlag, J., and M. Waszah (1971) Electrophysiological properties of units of the thalamic reticular complex. Exp. Neurol. 32: 79-97.

Shiosaka, S., K. Takatsuki, M. Sakamaka, S. Inagaki, H. Takagi, E. Senba, Y. Kawai, H. Iida, H. Minagawa, Y. Hara, Y. Matsuzaki, and N. Tohyama (1982) Ontogeny of somatostatin-containing neuron system of the rat: Immunohistochemical analysis. II. Forebrain and diencephalon. J. Comp. Neurol. 204: 211-224.

Silver, A. (1974) The Biology of Cholinesterases, ElsevierNorth Holland Publishing Co., New York.

Speiss, J., and W. Vale (1980) Multiple forms of somatostatinlike activity in the rat hypothalamus. Biochemistry 19:28612866

Srikant, C. B., and Y. C. Patel (1981) Somatostatin analogs. Dissociation of brain receptor binding affinities and pituilary actions in the rat. Endocrinology 108: 341-343.

Sternberger, L. A. (1979) Immunocytochemistry, John Wiley \& Sons, Inc., New York.

Sugimori, M., R. J. Preston, and S. T. Kitai (1978) Response properties and electrical constants of caudate nucleus neurons in the cat. J. Neurophysiol. 41: 1662-1675.

Swanson, L. W., W. M. Cowan, and E. G. Jones (1974) An autoradiographic study of the efferent connections of the ventral lateral geniculate nucleus in the albino rat and the cat. J. Comp. Neurol. 156: 143-164.

Takatsuki, K., S. Shiosaka, S. Inagaki, M. Sakanaka, H. Takagi, E. Senba, T. Matsuzaki, and M. Tohyama (1981) Topographic atlas of somatostatin-containing neuron system in the avian brain in relation to catecholamine-containing neuron system. I. Telencephalon and diencephalon. J. Comp. Neurol. 202: 103-113.

Veening, J. G. (1978) Subcortical afferents of the amygdaloid complex in the rat: An HRP study. Neurosci. Lett. 8: 197202.

Vincent, S. R., I. Skirboll, T. Hökfelt, O. Johansson, I. M Lundberg, R. P. Elde, L. Terenius, and J. Kemmel (1982) Coexistence of somatostatin and avian pancreatic polypeptide (APP)-like immunoreactivity in some forebrain neurons. Neuroscience 7: 439-446. 